\title{
Application of High Performance Thin Layer Chromatography in Examination of Magenta Coloured Printed Matter
}

\author{
Rashmi Sharma ${ }^{1}$; T. R. Baggi ${ }^{2}$; Amit Chattree ${ }^{3}$; A. K. Gupta ${ }^{4}$ \\ ${ }^{I}$ Senior Scientific Assistant, Forensic Science Laboratory, Rohini, Delhi-110085, India. \\ ${ }^{2}$ Academic Coordinator, Department of Chemistry, University College of Science, Osmania University, \\ Hyderabad, A.P. 500007, India. \\ ${ }^{3}$ Head, Department of Chemistry, Department of Chemistry, SHIATS, Allahabad, U.P.-211007, India. \\ ${ }^{4}$ Head, Department of Forensic Science, Department of Forensic Science, SHIATS, Allahabad, U.P.-211007, \\ India.
}

\begin{abstract}
The technique of High Performance Thin Layer Chromatography was utilized to separate the components of magenta colour inkjet printer ink. An attempt has been done to develop a protocol to examine and opine on the issue of identification of printer from which a document was printed.
\end{abstract}

\section{Introduction}

From the moment that a writing ink is applied to paper material, the chemical composition of ink begins to undergo changes. Various physical and chemical processes occur such as the evaporation of solvent; spreading of ink, paper corrosion etc. Modern inks are the mixtures of various components to provide different physical and chemical properties to ink such as colorants (dyes or pigments), Solvent, surfactants, humectants, biocides, fungicides, buffering agents and resins. Additionally, other organics may be used to control corrosion or improve solubility of the dyes and pigments. Current methods for the examination, identification and comparison of inks on paper include a wide variety of techniques, ranging from optical examination, microscopic and spectroscopic studies of the ink. Some techniques require damaging the sample by mechanical or chemical removal of ink from paper. Various forms of chromatography such as column, paper, thin layer, gas and liquid chromatography have gained prominence from past several decades to separate the components of inks. Thin Layer Chromatography involves a stationary phase through which a solvent system migrates across the plate by capillary action, separating the ink components. The process involves carrying the components of ink by a mobile phase through a stationary phase. The separation of dyes, colourless organic components as well as non-volatile components occurs due to their different migration rates. The several samples can be examined on the same TLC plate whereas the TLC densitometry is used in absorption or reflection mode in visible/UV254/UV366 mode to determine the relative concentrations of the dyes present and other components. In the present study the fast, reliable, and economical technique of HPTLC was used for direct comparison and identification of ink. The technique involves use of very small sample and is sensitive because of the intense colour of dye components in the visible region, absorption in UV region and fluorescence.

\subsection{Sampling}

\section{Experimental}

Thirty two (32) coloured printouts each containing four rectangular blocks of cyan, magenta, yellow and black colour were printed from inkjet printers of four leading manufacturers. White paper of A4 size from same company was used to take all samples. The colours were selected by following RGB model. All four printed colour i.e. cyan, magenta, yellow and black from each printout were extracted and analyzed. The four leading brands were marked as $\mathrm{A}, \mathrm{B}, \mathrm{C}$ and $\mathrm{D}$ and their different models were marked as $1,2,3$ and so on. The samples were given marking as $1,2,3,4,5,6,7,8,9,10,11,26,27,28,30,31,32$ for different models of brand ' $\mathrm{A}$ ', $16,18,19,23,24,29$ for different models of brand ' $\mathrm{B}$ ', 12,13,20,21 for different models of brand ' $\mathrm{C}$ ' and $14,15,17,22,25$ for different models of brand ' $\mathrm{D}$ '. A Magenta coloured piece of squared block from constant area was taken from the sample document and cut into pieces. The ink was then extracted from the paper using methanol at room temperature with intermittent trituration. To check its adaptability to real case the examination was carried out by extracting ink from 10 microplugs of the printed documents using methanol.

15 microlitre solution of sample was sprayed as bands of $6 \mathrm{~mm}$ from ATS 4 (Automatic TLC Sampler). The samples were applied $2.5 \mathrm{~cm}$ from the bottom of the plates, starting $2.5 \mathrm{~cm}$ from the left side of the plate and distance between bands $1 \mathrm{~cm}$ was maintained. This configuration allows the application of 16 tracks on a 20 $\mathrm{cm}$ X10 $\mathrm{cm}$ plate thus 32 samples can be applied on the two plates. Before the application of sample solution the ATLC plates were activated in oven at $100^{\circ} \mathrm{C}$ for 15 minutes. Many solvent solvents were tried for the fine separation of components of magenta coloured ink but solvent system, n-Butanol: Acetone: Distilled water: 
Ammonia (25:25:5:17.5) was found best for the separation of magenta Inkjet Inks. The chamber was saturated to equilibrate the solvent system for 20 minutes. The mobile phase was allowed to migrate till $6 \mathrm{~cm}$ from the origin point of plate.

\subsection{Hptlc Instrumentation Parameters}

A HPTLC instrument from Camag, Switzerland with computer system and installed Cats Software Version 1.4.2 was used. TLC Scanner II was employed for scanning of developed TLC plate and ATS 4 as an application device. Precoated ATLC plates with silica Gel $60(20 \mathrm{~cm} \times 10 \mathrm{~cm})$ from Merck were used. The TLC plates were developed in twin trough Chamber (TTC) to accommodate standard $20 \mathrm{~cm} \mathrm{X} 10 \mathrm{~cm}$ plate.

\section{Results And Discussion}

The aim of printing ink manufacturers is to fulfill the requirement of manufacturers of printers regarding the various characteristics of ink. Ink manufacturers are more interested in physical properties of ink keeping the economical considerations in mind. Ink manufacturers do not hesitate to replace ink components by cheaper ones so as physical properties of ink do not change. Thus examiners cannot rely on the characterization of every ink by the list of their components and individual identification of ink components requires an exhaustive reference collection of all possible chemical compounds that were, are and will be used by ink manufacturers. Although the creation and maintenance of such collection does not appear realistic in practice.

After development the spots were visualized at short wavelength and long wavelength UV. The printer users may use inks from different suppliers for a given model of instrument due to the mass manufacturing. The variation in the composition of the ink of a given brand/model of instrument is illustrated in chromatograms as given in figure 1.After separation of the ink components the plates were then scanned under TLC Scanner. The images of chromatogram were documented by using DigiStore2 documentation system (CAMAG) under UV 254 and $366 \mathrm{~nm}$.After separation the plates were viewed in day light, short wave $(254 \mathrm{~nm})$ and long wave (366 $\mathrm{nm})$ and the observation about the colour / fluorescence of the spots was recorded.

Different brands of Magenta coloured computer printer inks are showing discriminating differences by using visible, short wave UV and long wave UV observation whereas within the same brand discrimination is poor. Presently as limited numbers of components are being used by all the manufacture there are some limitations of comparison. As the technology gets more advanced more components may be added to coloured computer printing inks to improve the flow properties, fastness, brightness and reactivity with the paper etc., which would improve the discrimination power of the proposed method. As of now since most of the manufacturers are using same chemical components in varying quantities, we are getting appropriate repeatability of these components in different samples with the same Rf values. Major components being same we may have to largely depend on the minor components. Usually along with the questioned document the suspected printer is submitted for examination to determine whether the particular printer was used to produce a particular printed document. The examination then can be carried out by taking a printout from the suspected printer and comparing the printer ink with questioned document ink by conducting physical and chemical analysis. As the investigation is carried out usually after a long time and it might be possible that the cartridges has been changed or worn out or refilled during that course of time. In such cases another printed document which was printed during or approximately same time is taken as an admitted specimen. That printout can be considered as a printed exemplar for comparison with the suspected printed documents. 


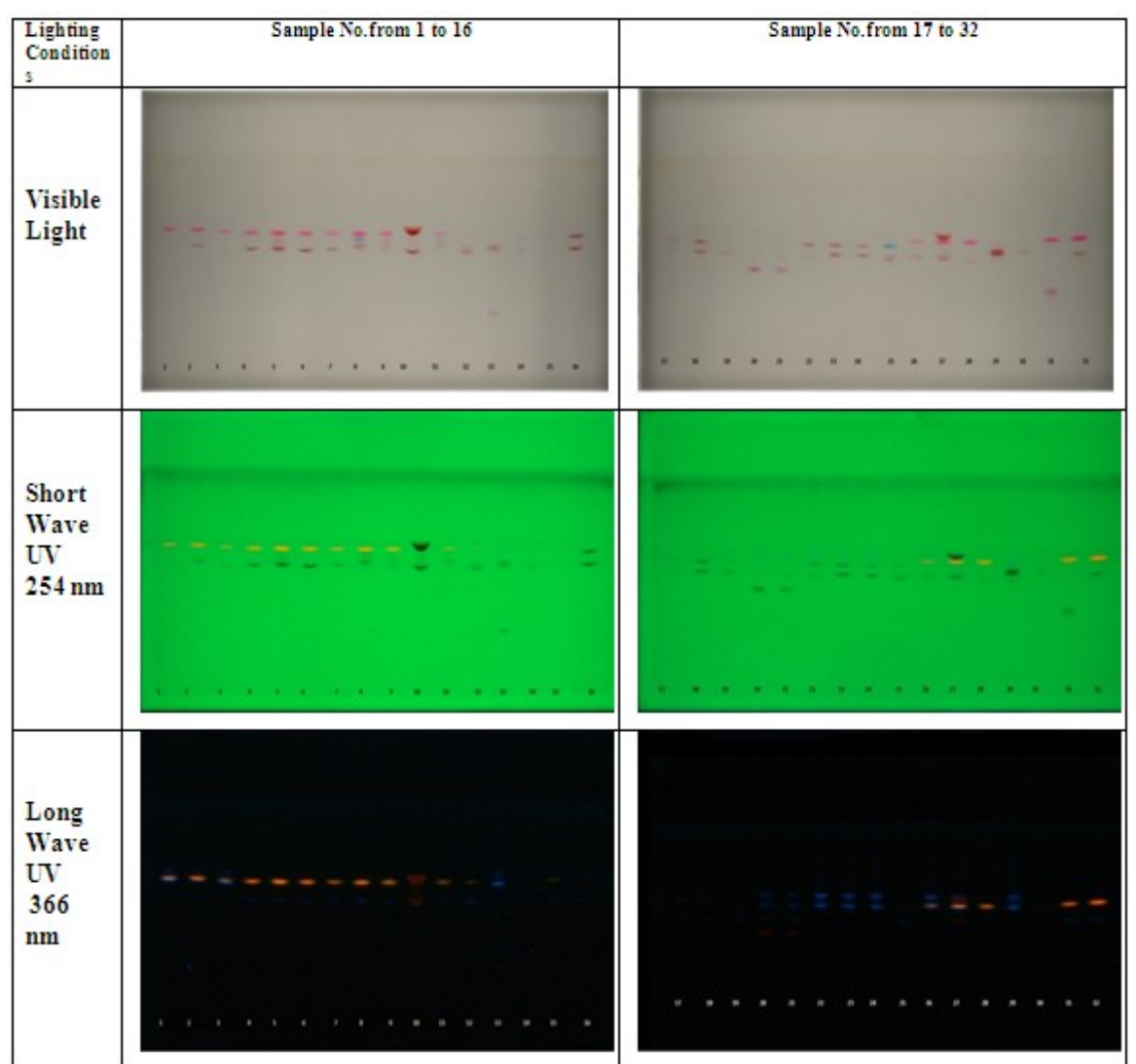

Figure no 1: Chromatograms obtained for different samples of Magenta ink in visible light, under short wave UV (254nm) and long wave UV (366nm) light.

If a data bank is built for the current Magenta coloured computer printing inks drawn from different manufacturers there is a fair chance of identifying the manufacturer of a questioned sample after taking into consideration various variable factors like storage condition, exposure to light, wear and tear etc. If an admitted sample from a questioned printer is given, the same can be compared with the suspect printed document by using this method to give a reliable opinion.

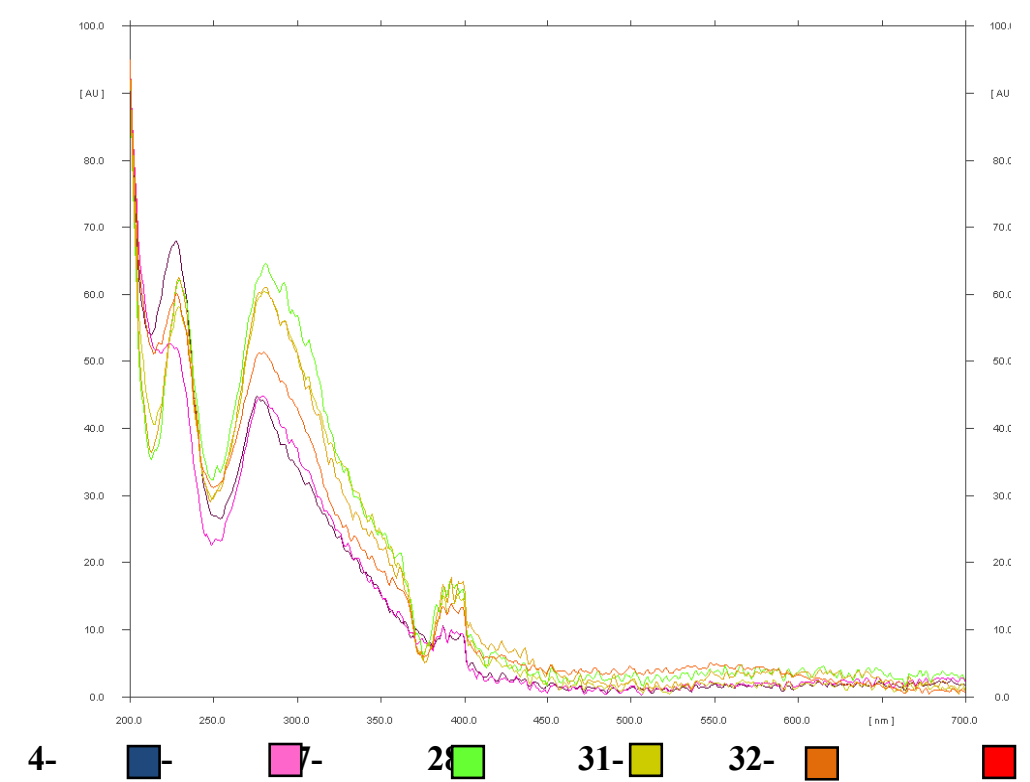

Figure no 2: A typical superimposition of spectra's of Magenta colour samples at Rf value of 0.44 . 
As a representative Figure no. 3 represents the number of spots obtained for specific printing ink from Brand 'A' for the discrimination of ink from same manufacturer. The opinion of source of questioned document encountered for examination can also be formed on the basis of number of spots obtained. Although this alone could not form the base of an opinion. The origin of printed document can be examined on the basis of all discriminating factors obtained after analysis of a sample from high performance thin layer chromatographic technique such as retention factor, number of spots obtained, colour of spots under visible light, fluorescence of spots under short wave and long wave UV etc. In case the samples are more then discrimination can be made on the basis of number of spots obtained for respective sample.

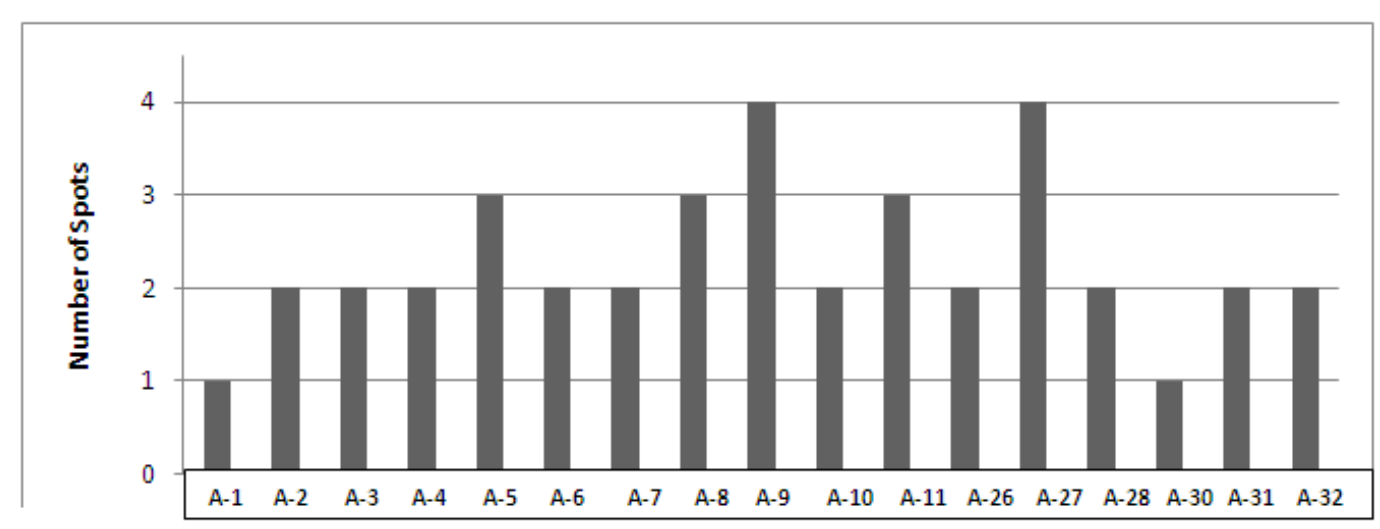

Figure no 3: Graphical representation of number of spots obtained for different ink samples of $B$ rand ' $A$ ' printer.

\section{Conclusion}

A simple and inexpensive High-Performance Thin-Layer Chromatography (HPTLC) technique employed for the analysis of Magenta colour printed ink extracted from 32 printed sample documents. Based upon the chromatogram developed \& after scanning each spots in densitometer it was observed that all spots are not consistent with each other. It's not always possible that output (printout) of two inkjet printers is same. Figure-2 indicates the some of the similar ink constituent in Magenta colored ink. But some differences are also found which might be due to the reason that some cartridges have been refilled by local ink manufacturer which may not be having exactly the same ink constituents as the original ink manufacturer. Slight variation in $\mathrm{Rf}$ of some spots is always remain due to different ink composition.

\section{Acknowledgements}

Corresponding author is thankful to Director cum Chief Forensic Scientist, Directorate of Forensic Science, GOI, New Delhi for providing Research Fellowship. The authors would like to thank Shri O.P.Murthy, Director, FSL Andhra Pradesh for permitting us to carry out this work in esteemed laboratory.

\section{References}

[1]. Aginsky V.N,Forensic Examination of 'slightly soluble' Ink Pigments using Thin Layer Chromatography. Journal of Forensic Sciences, 1993 ,38(5):1131-1133.

[2]. AginskyV. N., Comparative examination of inks by using instrumental Thin Layer Chromatography and Microspectrophotometry. Journal of Forensic Science, 1993, 38 (4-6): 1111-1129.

[3]. Anthony C.M., Osselton M.D. and Widdop B. Clarke's Analysis of Drugs and Poisons (in pharmaceutical, body fluids and postmortem material). Third edition. 2004, 313(1).

[4]. Arsov, Mesrob and Gateva.Thin-layer chromatography of basic dyes. Journal of Chromatography. 1973, 81:181-186.

[5]. Brunelle R.L., Negri J.F., Cantu A.A. and Lyter A.H. Comparison of typewriter ribbon inks by thin layer chromatography. Journal of Forensic Sciences. 1997, 22: 807-814.

[6]. Clement J.L. and Ceccaldi P.F.ATLC and study of inks. International Criminal Police Review. 1981, $350: 186$.

[7]. Djozan Dj., Baheria T., Karimi M.R. and Karimiand G. Forensic Discrimination of Blue Ballpoint Pen Inks Based on Thin Layer Chromatography and Image Analysis. Forensic Science International. 2008, 179(2-3):199-205.

[8]. Ellen, D. The Scientific Examination of Documents. Ellis Horwood Limited.1989,122-137.

[9]. Jasuja O.P., Singla A K., and Seema B.L. Thin Layer Chromatographic Analysis of Indian Stamp Pad Inks. Forensic Science International. 1989, 42(1,2): 255-262.

[10]. Jasuja O.P. and Sharma R. Thin layer Chromatographic Analysis of Some Printing Inks. International Journal of Forensic Document Examiners. 1997,3(4):356-359.

[11]. Kaur S., Saroa J. S. and Sharma R.M. Thin Layer Chromatography of Some Common Carbon Papers. The Forensic Scientist OnLine Journal. 2006, 9: 1-9.

[12]. Kaur S., Saroa J. S. and Sharma R.M. Thin Layer Chromatography of Some Common Carbon Papers. The Forensic Scientist OnLine Journal. 2006, 9: 1-9.

[13]. Kelly and Lindblom. Scientific Examination of Questioned Documents. Thomas Publisher, 2006, USA. 
[14]. Lyter A. H. Reflectance Spectrophotometric Examination of the Thin-Layer Chromatography Separation of Writing Ink: I. Dye Separation, Reproducibility and Linearity: A Quantitative method to differentiate between subtle differences in thin layer chromatograms of writing inks. Forensic Document Examination. 2003, 6(1).

[15]. Neumann, C. and Margot, P. New perspectives in the use of ink evidence in forensic science: Part I. Development of a quality assurance process for forensic ink analysis by ATLC. Forensic Science International. 2009,a, 185(1-3'):29-37.

[16]. Neumann C. and Margot P. New perspectives in the use of ink evidence in Forensic Science Part II. Development and Testing of Mathematical Algorithms for the Automatic comparison of ink samples analyzed by ATLC. Forensic Science International. 2009,b, 185(1-3):38-50.

[17]. Pagano L.W., Surrency M.J. and Cantu A.A.. Inks: Forensic Analysis By Thin layer (planar) Chromatography. US Secret Service, Washington DC, USA. 2012, 3101-3109.

[18]. Saini K., Singh J. and Hundal G.S.Thin Layer Chromatography of color inkjet inks. The Indian Journal of Criminology and Criminalistics. XXVIII. 2007,(1):74-89.

[19]. Saini K. and Saroa J.S. Thin Layer chromatography of refilled photocopy toners. Journal of Forensic Identification.2008, 58(3): 305-316.

[20]. Senior S., Hamed E., Masoud M. and Shehata E. Characterization and dating of blue ballpoint pen inks using principal component analysis of UV-Vis absorption spectra, IR spectroscopy, and ATLC. Journal of Forensic Science. 2012, 57(4):1087-93.

[21]. Sidhu, T.K. Thin Layer Chromatographic Analysis of Inkjet Printer Inks. A Report submitted to Punjabi University, Patiala (Unpublished Work).

[22]. Stahl, E. Thin Layer Chromatography, A Laboratory Handbook. Second Edition. Springer-Verleg Berlin Heideberg,1969, New York.

[23]. Tandon G., Jasuja O.P. and Sehgal V.N. Thin Layer Chromatography analysis of photocopy toners. Forensic Science International. 1995, 73: 149-154.

[24]. Tappolet J.A. The High Performance Thin Layer Chromatography. Its Application to the Examination of Writing Inks. Forensic Science International. 1983, (22)1:99-109.

[25]. Tiwari S.N. and Bhatt N. Thin layer Chromatographic analysis of Indian fountain pen inks. International Criminal Police review. 1972.260: 201-203.

[26]. Totty, R.N., Ordidge, M.R. and Onion, L.J.A comparison of the use of visible microspectrometry and high performance thin layer chromatography for discrimination of aqueous inks used in porous tip and roller ball pens. Forensic Science International. 1985, 28:137-114.

[27]. Varshney, K.M., Jettapa, T., Mehrotra, V.K., and Baggi, T.R. Ink Analysis From Typed Script of Electronic Typewriters by High Performance Thin Layer Chromatography. Forensic Science International.1995, 72(2):107-115.

[28]. Verma, R.S., Prasad, K. N., and Mishra, G. Thin Layer Chromatographic Analysis of Fibre-Tip Pen Inks. Forensic Science International.1979, 13: 65-70.

[29]. Varshney, K.M. and Mehrotra, V.K. A non destructive technique using a TLC Scanner for currency for currency notes color characterization and alike material. International Journal of Forensic Document Examiners. 1998, 4 (4):336-339. 